\title{
ANALISIS PARAMETER OSEANOGRAFI MELALUI PENDEKATAN SISTEM INFORMASI MANAJEMEN BERBASIS WEB (Sebaran Suhu Permukaan Laut, Klorofil-a dan Tinggi Permukaan Laut)
}

\author{
Rochmady \\ Staf Pengajar STP - Wuna, Raha, e-mail : kampo.mokesano@gmail.com
}

\begin{abstract}
ABSTRAK
Penelitian dilakukan bertujuan untuk menganalisis anomali parameter oseanografi yang meliputi suhu permukaan laut (SPL), sebaran klorofil-a dan tinggi permukaan laut selama musim timur (April-Juni 2007) dan musim barat (Nopember 2007-Januari 2008) di perairan Selat Buton sebagian Laut Banda dengan posisi geografis $120^{\circ}-$ $125^{\circ}$ BT dan $1^{\circ}-8^{\circ}$ LS. Hasil penelitian menunjukkan bahwa berdasarkan peta suhu permukaan laut (SPL) pada musim timur terjadi penurunan derajat suhu permukaan laut dari bulan April menuju bulan Juni. Penurunan derajat SPL pada bulan Juni tersebut diduga mengakibatkan terjadinya upwelling. Namun demikian, peristiwa upwelling tersebut tidak terjadi pada musim barat. Berdasarkan peta sebaran khlorofil-a terlihat bahwa konsentrasi khlorofil-a semakin meningkat dari bulan April hingga menuju bulan Juni 2007. Hal ini mengindikasikan terjadinya peristiwa upwelling pada musim timur. Sementara itu, berdasarkan peta sebaran tinggi permukaan laut (TML) terlihat bahwa karakteristik tahunan tinggi permukaan laut mengalami penurunan pada musim timur dan sebaliknya mengalami peningkatan pada musim barat. Berdasarkan ketiga parameter oseanografi tersebut diketahui bahwa potensi penangkapan ikan terjadi pada musim timur dan berangsur-angsur menurun pada musim barat. Hal ini disebabkan terjadinya penurunan derajat SPL dan konsentrasi khlorofil-a serta menurunnya tinggi permukaan laut pada musim timur yang kaya akan nutrien dan berangsur-angsur mengalami penurunan pada musim barat.
\end{abstract}

Kata Kunci: Parameter Oseanografi, SIM.

\section{PENDAHULUAN}

1.1. Latar Belakang

Perkembangan teknologi informasi manajemen melalui penginderaan jauh berbasis website, telah memberi manfaat dan memudahkan dalam memetakan kondisi perairan khususnya di Indonesia. Perkembangan tersebut secara aktual dapat dimanfaatkan dalam berbagai bidang kehidupan, khususnya dalam bidang perikanan tangkap. Selain itu pula, informasi penginderaan jauh dapat diperoleh dengan mudah dan murah (Sukresno, 2008). Selanjutnya dikatakan bahwa informasi penginderaan jauh dapat dianalisis dan dimanfaatkan khususnya bidang perikanan antara lain untuk mengidentifikasi kondisi lingkungan perairan yang dibutuhkan oleh ikan pelagis tertentu untuk hidup dan berkembang biak. Distribusi ikan pelagis seperti madidihang dapat diprediksi melalui analisis suhu optimum yang diketahui dan perubahan-perubahan suhu permukaan laut (SPL) dari waktu ke waktu secara simultan (harian maupun bulanan) (Laevastu dan Hela, 1970).

Demikian pula suhu dan perubahanperubahannya sering dijadikan sebagai indikator bagi kondisi perairan maupun perubahanperubahan lingkungan yang dapat 


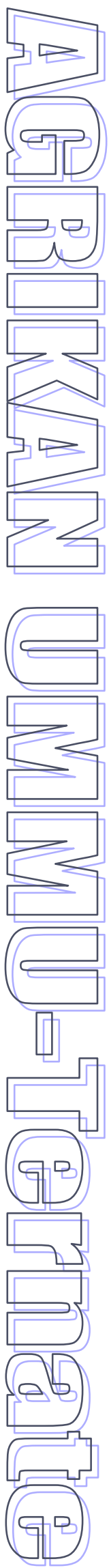

mempengaruhi distribusi ikan secara langsung, yang selanjutnya dapat diprediksi sebagai lokasi fishing ground (tempat penangkapan ikan pelagis/lumbung ikan) (Utamaningsih, 1995).

Pendekatan tersebut telah banyak digunakan oleh nelayan utamanya nelayan asing untuk mengetahui daerah potensi penangkapan ikan, termasuk yang ada di perairan Indonesia yang terkenal kaya dengan sumberdaya lautnya (Utamaningsih, 1995). Informasi lingkungan perairan dari data satelit yang telah banyak digunakan untuk keperluan tersebut antara lain suhu permukaan laut (SPL), konsentrasi khlorofil-a yang merupakan pigmen penting dalam proses fotosintesis fitoplankton sebagai indikator kesuburan perairan, total material terlarut (total suspended matter) yang dapat merefleksikan kekeruhan perairan, dan anomali tinggi permukaan laut (TML) yang dapat menggambarkan arah arus permukaan air (Zainuddin, 2008).

\subsection{Tujuan Penelitian}

Penelitian bertujuan menganalisis anomali parameter oseanografi meliputi suhu permukaan laut (SPL), sebaran khlorofil-a dan tinggi permukaan laut selama musim timur (April-Juni 2007) dan Musim Barat (Nopember 2007-Januari 2008), di perairan laut Sulawesi Tenggara yakni Selat Buton dan sebagian besar Laut Banda, dengan posisi Geografis $120^{\circ}-125^{\circ} \mathrm{BT}$ dan -1 - -8 LS. Dengan mengetahui kondisi anomali parameter oseanografi meliputi suhu permukaan laut (SPL), sebaran khlorofil-a dan tinggi permukaan laut selama musim timur dan musim barat, dapat dijadikan sebagai bahan informasi dasar yang berguna dalam penentuan daerah dan musim penangkapan yang ideal.

\section{METODE PENELITIAN}

2.1. Waktu dan Lokasi Penelitian

Penelitian parameter oseanografi meliputi suhu permukaan laut (SPL), khlorofil-a dan tinggi permukaan laut (TML) dilaksanakan pada bulan Februari-Mei 2010 dengan melakukan pemantauan pada musim timur (April-Juni 2007) dan musim barat (Nopember 2007-Januari 2008) di perairan laut Sulawesi Tenggara yakni Selat
Buton dan sebagian besar Laut Banda pada posisi geografis $120^{\circ}-125^{\circ} \mathrm{BT}$ dan $-1-\quad-8$ LS. Data diperoleh melalui situs ccar.colorado.edu dan dianalisis secara deskriptif berdasarkan data geografis yang diperoleh.

\subsection{Teknik Pengambilan Sampel}

Alat yang digunakan dalam penelitian meliputi komputer berbasis internet untuk mengakses web penyedia informasi oseanografi meliputi suhu permukaan laut (SPL), sebaran khlorofil-a dan tinggi permukaan laut (TML). Bahan yang digunakan merupakan data geografis berupa suhu permukaan laut (SPL), sebaran khlorofil-a dan tinggi permukaan laut.

\subsection{Prosdur Penelitian}

Penelitian dilakukan dengan cara memantau sebaran beberapa parameter oseanografi meliputi: Suhu Permukaan Laut (SPL), sebaran khlorofil-a dan Tinggi Permukaan Laut (TML) yang terjadi pada perairan Sulawesi Tenggara yang terletak di Selat Buton dan sebagian Laut Banda berbasis satelit. Pemantauan dilakukan setiap hari selama Musim Timur yaitu bulan April, Mei dan April Tahun 2007, dan pada Musim Barat yaitu bulan Nopember, Desember 2007 dan Januari Tahun 2008. Sumber informasi satelit disediakan melalui website ccar.colorado.edu.

Hasil pemantauan terhadap 3 (tiga) parameter oseanografi tersebut, kemudian dijadikan dasar informasi untuk membandingkan dan menganlisis secara diskriptif fenomena anomali ketiga parameter tersebut.

\section{HASIL DAN PEMBAHASAN}

3.1. Peta Sebaran Suhu Permukaan Laut

Suhu permukaan air laut sangat erat hubungannya dengan produktifitas primer dan arus laut (Arsjad, 2004). Perubahan suhu permukaan air laut disebabkan arus, angin, kekeruhan air serta ombak, biasa disebut dinamika laut. Hasil pemantauan suhu permukaan laut (SPL) musim timur dan musim barat di perairan Sulawesi Tenggara di selat 


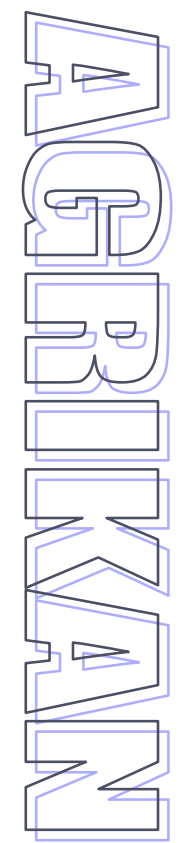

Buton dan sebagian Laut Banda dapat dilihat pada Gambar 1 dan 2.

Berdasarkan Gambar 1 di atas, suhu permukaan laut (SPL) mengalami penurunan dari bulan April ke bulan Juni. Bulan Juni diprediksi telah terjadi upwelling atau dari lapisan perairan yang lebih dalam ke permukaan. Fenomena upwelling di perairan Laut Banda biasanya berlangsung sepanjang musim Timur. Namun demikan, peristiwa upwelling tidak terjadi pada musim Barat, seperti terlihat pada Gambar 2. pengangkatan massa air dengan suhu rendah
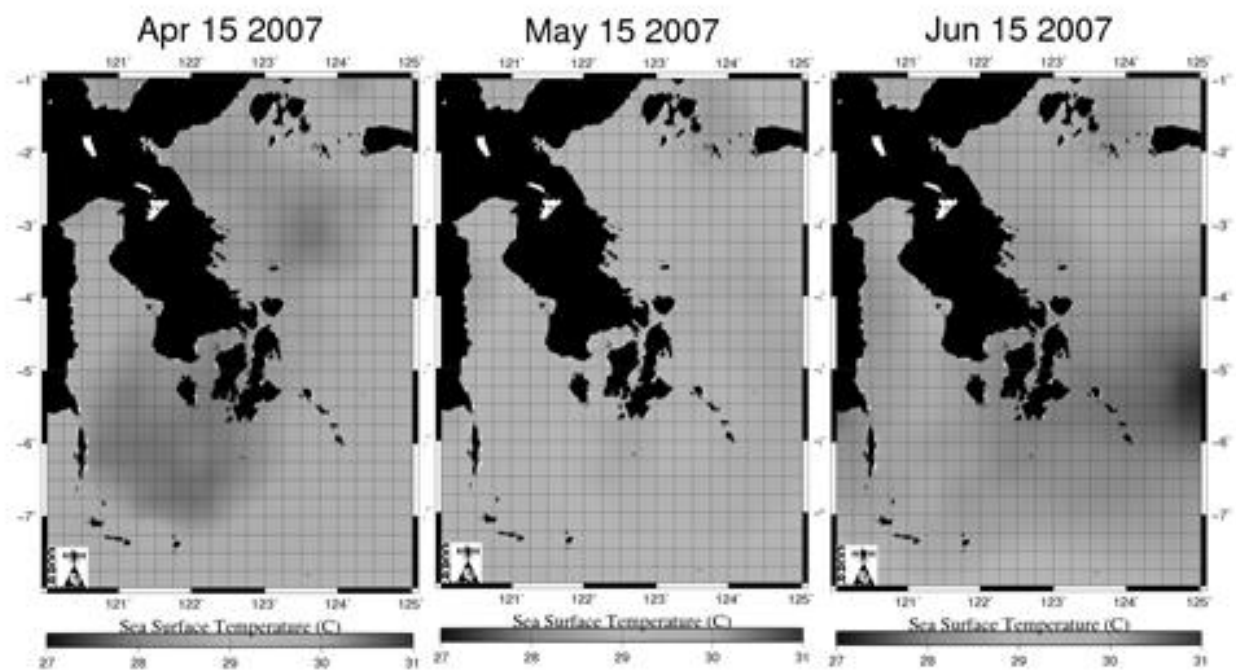

Gambar 1. Sebaran Suhu Permukaan Laut perairan Sulawesi Tenggara di Selat Buton dan sebagian besar Laut Banda selama Musim Timur (Apr-Jun 2007).

Nov 152007

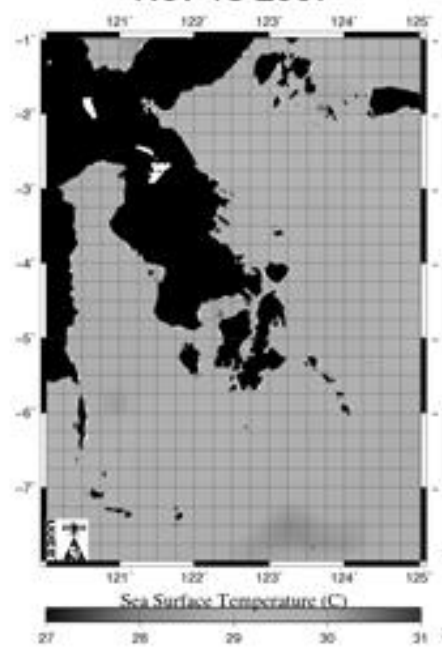

Dec 152007

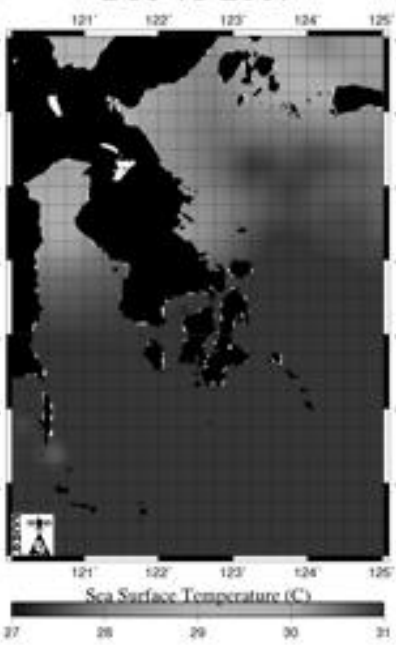

Jan 152008

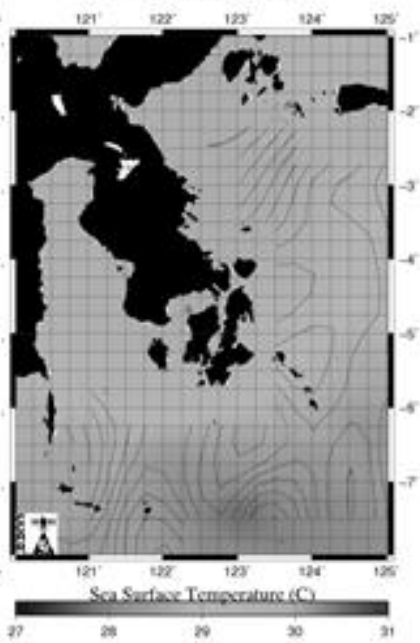

Gambar 2. Sebaran Suhu Permukaan Laut perairan Laut Sulawesi Tenggara di Selat Buton dan sebagian besar Laut Banda selama musim Barat (Nov 2007-Jan 2008).

Proses upwelling yang terjadi di suatu perairan ditengarai mempengaruhi kondisi kehidupan fitoplankton, hidrologi dan pengayakan nutrisi di perairan tersebut. Disisi lain, kondisi fitoplankton baik keanekaragaman dan distribusinya turut dipengaruhi oleh berbagai faktor lain, seperti atmosfer, lokasi dan kondisi lingkungan perairan. Proses upwelling 


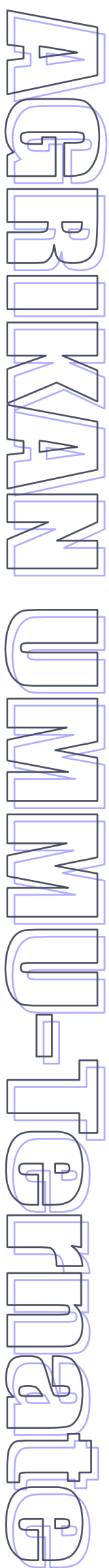

di Laut Banda di duga terjadi karena pengaruh angin musim yang berasal dari arah tenggara. Menurut teori Wyrtki, angin tenggara pada musim timur (April-Juni) mendorong banyak massa air dari Laut Banda dan sekitarnya ke barat melalui Laut Flores dan masuk ke Laut Jawa.

3.2. Peta Sebaran Khlorofil-a di Perairan Laut Banda

Sebaran khlorofil-a dapat dideteksi dengan perubahan suhu yang mengarah pada peristiwa upwelling. Upwelling sebagai salah satu faktor yang mempengaruhi ledakan fitoplankton. Proses upwelling terjadi karena kekosongan massa air pada lapisan permukaan, akibat terbawa ke tempat lain oleh arus. Upwelling dapat saja terjadi di daerah pantai dan di laut lepas. Di daerah pantai, upweling dapat terjadi jika massa air lapisan permukaan mengalir meninggalkan pantai. Di laut lepas, upwelling terjadi karena adanya pola arus permukaan yang menyebar (divergence), sehingga massa air dari lapisan bawah permukaan akan mengalir ke atas mengisi kekosongan yang terjadi karena menyebarnya arus. Proses ini ditandai dengan turunnya suhu permukaan laut yang cukup mencolok (sekitar $2^{\circ} \mathrm{C}$ untuk daerah tropis, dan $>2^{\circ} \mathrm{C}$ untuk daerah sub tropis) (Dahuri et al., 1996).

Upwelling yang terjadi di perairan Laut Banda adalah jenis silih berganti (alternating type) dengan penenggelaman massa air (sinking). Dalam satu musim, air ringan di lapisan permukaan bergerak ke luar dari lokasi terjadinya air naik dan air lebih berat di lapisan bawah bergerak ke atas yang kemudian tenggelam. Berdasarkan hal tersebut, sebaran khlorofil-a di perairan laut Sulawesi Tenggara dapat dilihat pada Gambar 3 dan 4.

Pada Gambar 3 terlihat konsentrasi khlorofil-a semakin meningkat dari bulan April menuju bulan Juni 2007. Hal ini diduga karena adanya fenomena upwelling yang mengangkut nutrient (nitrat dan fosfat) dari perairan dalam menuju permukaan selama musim Timur. Menurut Nontji (2008), menurunnya suhu permukaan, keberadaan upwelling juga ditandai oleh naiknya unsur hara atau nutrien pada lokasi tersebut, oleh karena massa air bawah permukaan pada umumnya lebih kaya zat hara dibanding dengan lapisan permukaannya. Nutrien, khususnya fosfat dan silikat di zona fotik sangat berpengaruh terhadap produktivitas fitoplankton, oleh karena itu pada lokasi upwelling akan ditemui fitoplankton dalam jumlah besar.

Berdasarkan Gambar 3, potensi tangkapan ikan paling besar terjadi pada saat musim angin Timur dengan SPL rendah dan konsentrasi chlorofil-a tinggi pada bulan Juli sampai September. Angin Timur mengakibatkan terjadinya upwelling di sepanjang pantai Selatan. Dengan demikian nutrient naik ke permukaan laut dari kedalaman sekitar $50 \mathrm{~m}$ sampai $100 \mathrm{~m}$, menyebabkan tingginya konsentrasi khlorofil-a. Potensi tangkapan ikan akan menurun seiring dengan berubahnya musim menuju musim angin Barat (Gambar 4) dengan naiknya SPL dan menurunnya konsentrasi khlorofil-a dari bulan Oktober sampai Maret.

pada Gambar 5 menunjukkan karakteristik tahunan Tinggi Muka Laut (TML) yang dipengaruhi oleh curah hujan, dan SPL. TML mengalami peningkatan pada saat terjadi curah hujan tinggi dan SPL yang tinggi. Hal ini akan menurun mencapai TML terendah pada bulan April-Juni saat curah hujan dan Suhu Permukaan Laut (SPL) mencapai titik terendah. Curah hujan berperan sebagai fresh water flux (penambah masa air) pada waktu musim penghujan, sementara SPL berperan sebagai expansi termal atau penambahan volume air laut akibat kenaikan suhu air (Gambar 6).

Anomali tinggi permukaan laut dipengaruhi pasang surut, topografi, angin, arus laut, densitas dan tekanan air laut, serta faktor lainnya. Perbandingan antara kondisi suhu permukaan laut (SPL), konsentrasi khlorofil-a dan sebaran tinggi permukaan air laut diketahui berdasarkan Gambar 7.

Pada Gambar 7, penurunan suhu permukaan laut (SPL) diduga mengakibatkan peningkatan kandungan khlorofil-a perairan Sulawesi Tenggara di Selat Buton dan sebagian besar Laut Banda. Namun demikian, konsentrasi khlorofil-a berada pada suhu permukaan laut optimumnya. Dengan demikian tidak secara 

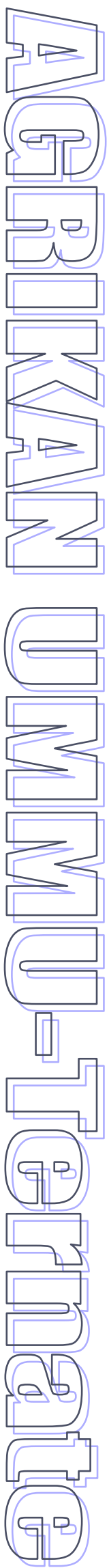

keseluruhan wilayah perairan Sulawesi Tenggara menunjukkan adanya khlorofil-a. Namun dapat dikatakan bahwa kandungan khlorofil-a mengalami peningkatan seiring dengan meningkatnya SPL sebagaimana dijelaskan sebelumnya.

Sementara itu, meningkatnya suhu perairan mengakibatkan penurunan tinggi permukaan laut, begitu pula sebaliknya. Dengan demikian, diduga terdapat korelasi negatif antara suhu dan tinggi permukaan laut. Diduga ubungan antara khlorofil-a dengan tinggi permukaan laut dapat didefenisikan berkorelasi negatif, yakni peningkatan chlorofil-a justru pada kawasan perairan dengan tinggi permukaan laut yang lebih rendah dibandingkan dengan kawasan perairan yang kandungan khlorofil-a rendah.

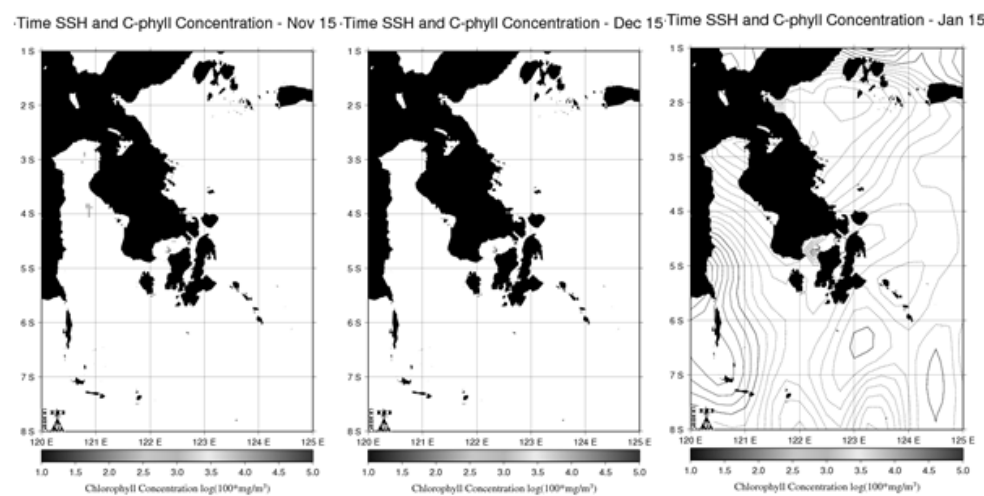

Gambar 3. Sebaran khlorofil-a perairan Laut Sulawesi Tenggara di Selat Buton dan sebagian besar Laut Banda selama musim Timur (Apr-Jun 2007).

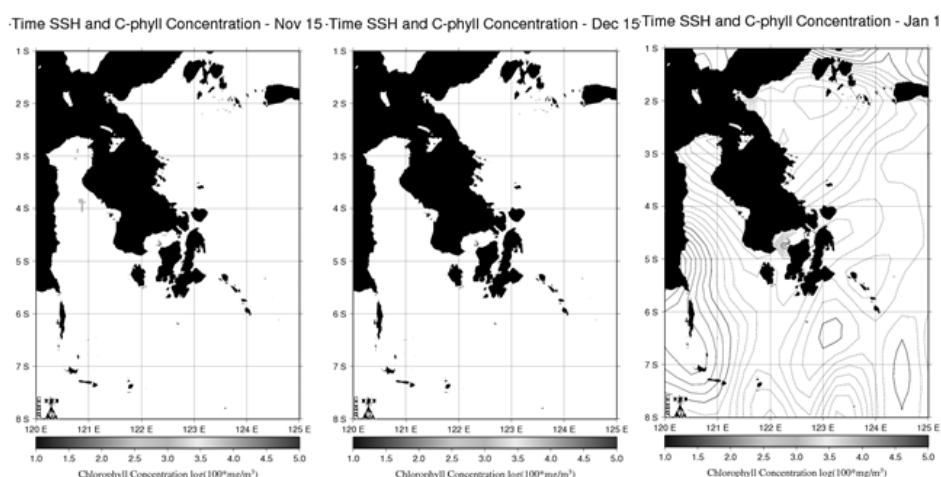

Gambar 4. Sebaran Chlorofil-a perairan Laut Sulawesi Tenggara di Selat Buton dan sebagian besar Laut Banda selama Musim Barat (Nov 2007-Jan 2008).

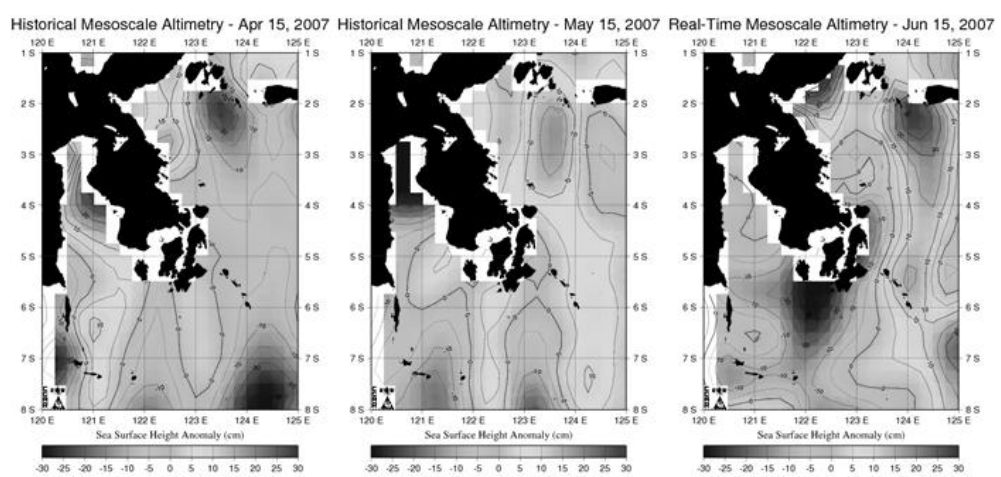

Gambar 5. Sebaran Anomali Tinggi Permukaan Laut (TML) perairan Laut Sulawesi Tenggara di Selat Buton dan sebagian besar Laut Banda selama Musim Timur (Apr-Jun 2007). 

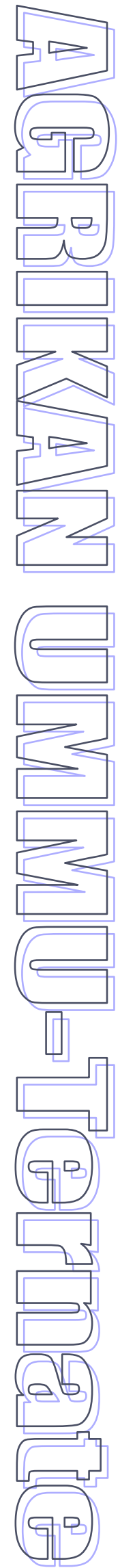

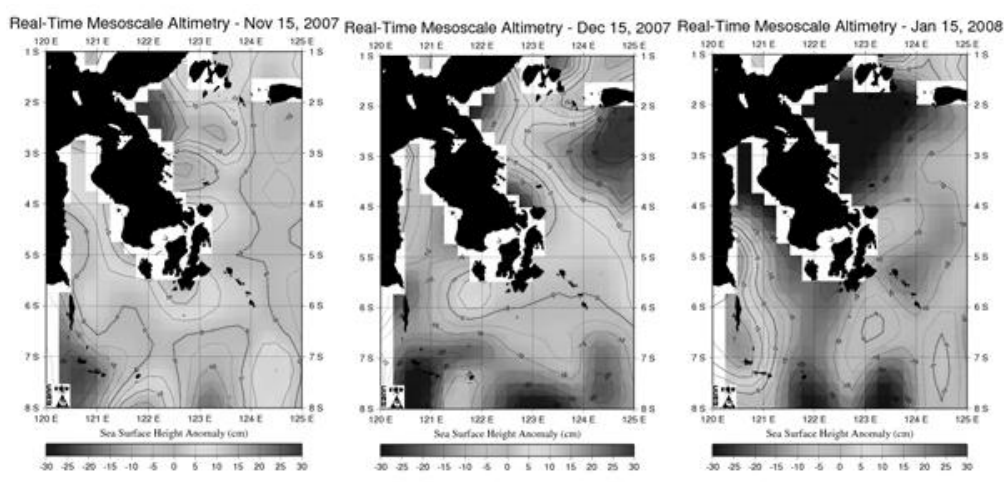

Gambar 6. Sebaran Anomali Tinggi permukaan laut di perairan Laut Sulawesi Tenggara di Selat Buton dan sebagian besar Laut Banda selama Musim Barat (Nov 2007-Jan 2008).
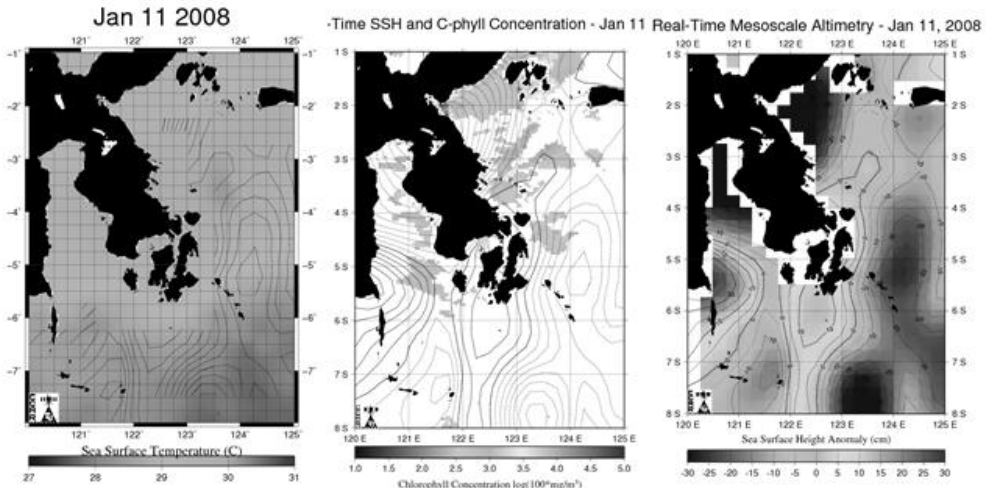

Gambar 7. Hubungan Suhu, Chlorofil-a dan Tinggi Muka Laut.

\section{PENUTUP}

\subsection{Kesimpulan}

Berdasarkan hasil dan pembahasan, dapat disimpulkan sebagai berikut.

a. Suhu permukaan laut mengalami penurunan dari bulan April menuju bulan Juni 2007. Pada bulan Juni diprediksikan telah terjadi upwelling, namun tidak terjadi pada musim barat pada bulan Nopember 2007-Januari 2008.

b. Konsentrasi khlorofil-a mengalami peningkatan dari bulan April menuju bulan Juni 2007 atau selama musim Timur, namun tidak terjadi pada musim Barat yakni pada bulan Nopember 2007-Januari 2008.

c. Karakteristik tahunan Tinggi Muka Laut (TML) yang dipengaruhi oleh curah hujan, dan Suhu Permukaan Laut. TML tertinggi pada saat terjadi curah hujan tinggi dan SPL yang tinggi, dan akan menurun mencapai TML terendah pada bulan Juli-Agustus 2007, pada saat curah hujan dan Suhu Permukaan Laut (SPL) mencapai titik terendah.

d. Hubungan Suhu, Chlorofil-a dan Tinggi Muka Laut yakni penurunan SPL mengakibatkan peningkatan khlorofil-a di perairan Laut Banda. Sementara itu meningkatnya SPL menyebabkan penurunan tinggi permukaan laut.

\subsection{Saran}

Berdasarkan hasil penelitian disarankan agar dilakukan penelitian lebih komprehensif yakni dengan pembuatan peta pergerakan jenis ikan tertentu, yang dengan menitik beratkan pada kombinasi pengukuran lapangan dan aplikasi teknologi inderaja agar informasi yang ditampilkan lebih akurat mengenai pergerakan ikan berdasarkan parameter oseanografi.

\section{UCAPAN TERIMA KASIH}

Kepada Bapak Mukti Zainuddin, S.Pi., M.Sc., Ph.D yang telah membantu dalam memperoleh 
data oseanografi secara berkala serta menafsirkan dan memahami data yang diperoleh. Selain itu kepada pihak pengelolaan website CCAR yang telah menyediakan data secara cuma-cuma serta adanya kemudahan akses terhadap informasi tersebut. Untuk itu, kami mengucapkan terima kasih.

\section{DAFTAR PUSTAKA}

Arsjad, S.M., Y.Siswantoro dan R.S. Dewi. 2004. Sebaran Chlorofil-a di Perairan Indonesia Inventarisasi Sumberdaya Alam dan Lingkungan Hidup;. Pusat Survei Sumberdaya Alam Laut. BAKOSURTANAL. Bogor.

Dahuri, R., J. Rais., P. Ginting., M.J. Sitepu. 1996. Pengelolaan Sumber Daya Wilayah Pesisir dan Lautan Secara Terpadu, Pradnya Paramita, Jakarta.

Dharmawan, K.S.A. 2006. Studi Sea Level Rise Menggunakan Data Multi Satelit Alimetri. Email : sahaaswina@yahoo.com.

Hendriarti, N. 2008. Hubungan Antara Keberadaan Ikan Pelagis dengan Fenomena Oseanografi dan Perubahan Iklim Musiman Berdasarkan Analisis Data Penginderaan Jauh. Globë Volume 10 No.1 April $2008: 19$ - 25

Hutabarat, S. dan S.M. Evans. 2006. Pengantar Oseanografi. Djambatan. Jakarta.

Olili, A.H. 2003. Kajian Faktor Fisik yang Mempengaruhi Distribusi Ichtioplankton (Awal Daur Hidup Ikan). Makalah Falsafah Sains. Program Pasca Sarjana. Institut Pertanian Bogor. Bogor.

Nontji, A. 2005. Laut Nusantara. Djambatan. Jakarta.

Nontji, A. 2008. Plankton Laut. LIPI-Press. Jakarta.

Nybakken, J.W. 1992. Biologi Laut. Suatu Pendekatan Ekologis. Gramedia Pustaka Utama.

Sukresno, B. 2008. Pengolahan Data Satelit NOAA-A VHRR untuk Mengukur Suhu Permukaan Laur Rata-rata Harian. Balai Riset dan Observasi Kelautan, Pusat Riset Teknologi Kelautan (BRKP). Departemen Kelautan dan Perikanan.

Utamaningsih. S. 1995. Pendugaan Lokasi Upwelling dengan Menggunakan Data Penginderaan Jauh, Prosiding Seminar Kelautan Nasional 1995, 15-16 Nopember 1995. Jakarta.

Zainuddin, M., 2008. Pembuatan Peta Oseanografi: Modul Praktikum Berbasis Website Peta Informasi Sebaran Suhu Permukaan Laut, Khlorofil, dan Perbedaan Tinggi Permukaan Laut. Program Pascasarjana Universitas Hasanuddin, Makassar. 